\title{
Research on the Development and Application of the Teaching Management System about Geodesy Basis
}

\author{
Xin LIU \\ Kunming University
}

Keywords: geodesy, information technology, Optimal Design

\begin{abstract}
With the accelerating pace of information technology, networking, digital and intelligent as the representative of modern information technology is changing people's work, learning and life, but also to the cause of education has brought new development space. This paper is according to the geodesy course is a deepening teaching reform and improving teaching quality system, students can experience the advanced teaching method, learning content rich during school, and teachers can obtain a large number of advanced teaching information, promote interaction with the students, so that the overall quality and ability of teachers and students have been improved. Therefore, it is necessary to design and implement a course system based on geodesy.
\end{abstract}

\section{Introduction}

"Geodesy" is the basic course of Surveying and mapping to study the earth's shape and size as the basic purpose, is to measure and describe the earth and detect its changes, provide spatial information for human activities, the basic framework for constructing topographic surveying, engineering surveying [1-2], cartography and geographic information systems, marine surveying and mapping science. The related problems from teaching and needs analysis, according to the "basic" geodesy course construction index system and measurement data processing requirements [3-4],the relevant information of the whole process of teaching, which is with the theory of software engineering and measurement data processing theory, and using the combination of visual programming language VB and Word, Excel, Access, Flash and so on [5-6].

The full implementation of the system requirement analysis, system architecture, design, construction, form programming development, animation production, assembly, maintenance and other work integration system debugging and system development, implementation of geodesy based" teaching management system has the characteristics of openness, interactivity, autonomy, integration, aesthetics and other "," Curriculum "basis of Geodesy teaching and learning and management services [2].

\section{The Main Functions of the System}

The System development using visual programming language VB, Word, Excel, combined with Access and Flash, a good set of interface design, openness, interactivity, autonomy, integration, and appearance is equal and comprehensive services in the course of geodesy teaching. System management is according to management authority requirements, which judgments will be completed in the Load event of the system login form, and system permissions are set. The main system of teaching process management as the guidance and teaching behavior, we through the backstage database and the related form concentrated display of teaching team, teaching syllabus, teaching process, teaching courseware and teaching materials, which contains a large number of images and beautiful Flash animation. it is not only let students understand fully familiar with the teaching goal, teaching requirements teaching, and the teaching content, but also a deep understanding and easily grasp the knowledge, to achieve a multiplier effect.

System learning process management, as the main module of system design and development, is the concentrated expression of active learning, interactive learning and test learning. active learning system is designed so that the students in the induction and Inspiration of a lot of questions under the initiative, enthusiasm and creativity, focus on chapter learning objectives of active learning, 
active exploration, active thinking, active practice, "the force from the Fen, since the knowledge acquired," rich knowledge, feelings, development ability. Teaching and answering is the interactive module of system design, provide powerful communication function for students' learning. Students encounter problems, you can ask a specific teacher, ask for answers, of course, not for a teacher at random questions, any teaching team, teachers can give answers. In response to questions raised by the students, respond to the teacher's name, and then submit the content to the backend database, and then display it on the main page of the teaching question [7-8]. Moreover, students can solve problems in their study and verify their abilities. The test learning of the test system design can realize the students' self-test and test their mastery of the course knowledge. The test questions include multiple-choice questions, filling in the blanks, judging questions, simple answers, discussion questions and calculation questions. Students can according to the condition of generating some self-editing test paper, with use of students and teachers to finish the test paper, after practice, judge system, given the practice result, the standard answer, timely feedback, let the students constantly sum up, learn again.

Geodesy course is a basic subject of spatial information and the change of the earth, will inevitably involve the measurement data processing and calculation of ground surface, ellipsoid and a Gauss plane, in order to grasp the teaching effect, the geodetic data processing module is the focus of the system design and development. We coordinate system and geodetic coordinate system conversion "relates to the foundation of Geodesy" courses are: 1954 Beijing coordinate system, 1980 national geodetic coordinate system, Gauss Kruger coordinate system and WGS-84 coordinate system, the coordinate system conversion according to the mathematical model between programming. We select the white Searle earth theme solution method, using VB programming call the database to achieve positive and negative solution. The key is to find out the relation between the earth element on the ellipsoid and the corresponding elements on the sphere, and solve the interface on the sphere by solving the geodetic problem, as shown in Formula 1 [9-10].

$$
\sin (x)=\gamma_{0}+\sum_{n=1}^{\infty}\left(\gamma_{n} \cos \frac{n \pi x}{L}+\mu_{n} \sin \frac{n \pi x}{L}\right)
$$

The measurement calculation includes triangulation, traverse network, leveling net and so on. The Gauss plane is According to the Gauss projection after the three conditions, the central meridian is the straight line; constant length projection central meridian; conformal projection. The following ellipsoid elements are computed to the Gauss plane. The GUI is shown in Formula 1, ellipsoid element normalized to Gauss plane $\gamma$. Gauss projection coordinates calculation, convergence angle of the known point $\Psi$. We calculate the direction modification Delta, and the distance change Delta is $\mu$, coordinate conversion of adjacent zone, which is as Figure.1.

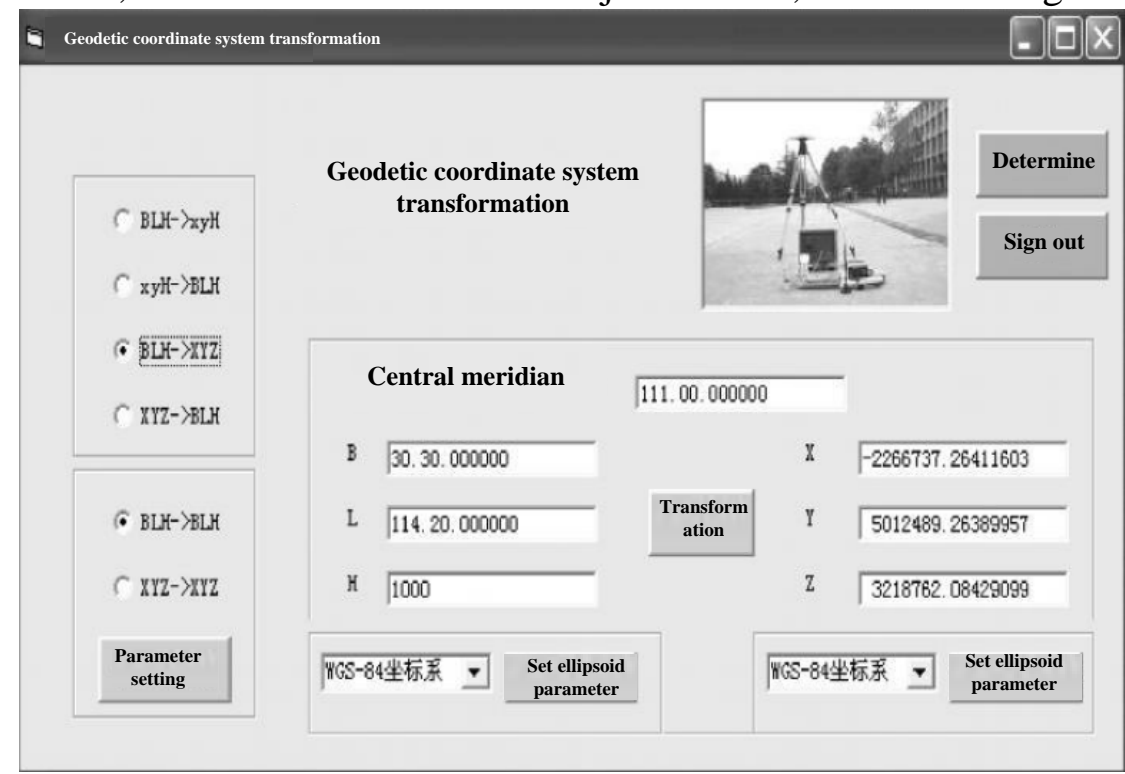

Fig.1. The geodetic coordinate system conversion 


\section{Test Results}

Geodesy teaching management system covers the whole process of teaching and learning, benefit by mutual discussion in the development process, and focus on the requirements of curriculum construction, comprehensive management of teaching documents and data processing, to ensure the practicality and system development content.

The system with documents, images, video, animation and other ways of all-round performance, teaching files, teaching notes, teaching courseware, teaching team, teaching materials, learning process, data processing, and strive to vivid performance way, which is to enable students to understand, easy to learn, easy to remember, easy to be effect. We is in order to improve the effect of students' learning system, try to select the interactive strategy, motivation and interactive quiz interviews, students not only passively accept, support the initiative of learning, make full use of geodetic data processing subsystem, real-time operation and mutual learning results, which is as Figure 2.

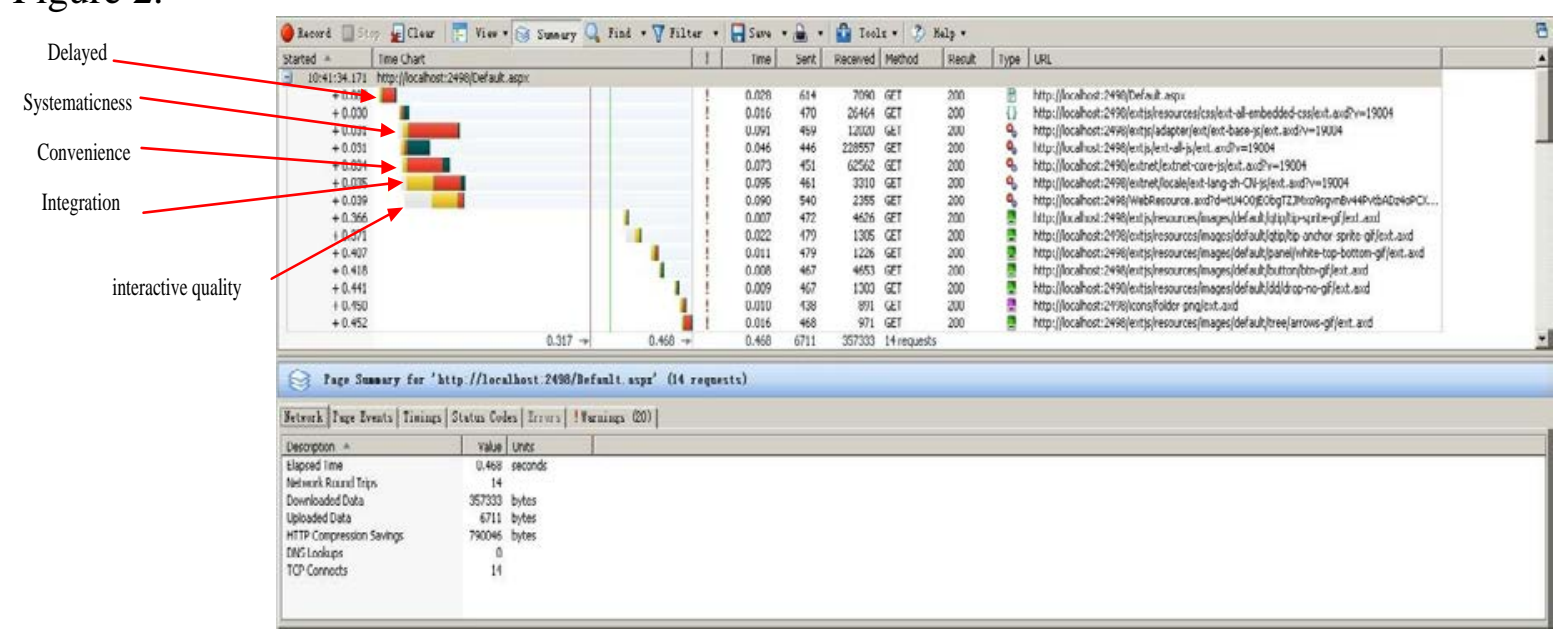

Fig.2. The system test performance

The system interface is friendly, which is clear [5], which is simple, the comprehensive use of VB, Word, Excel, Access and Flash system development, comprehensive assistance "geodesy foundation course" teaching and learning. The system programming has realized all data processing and calculation of the "geodetic basic course", designed the questions and answers, the prompt operation method, the reconciliation procedure and the easy operation. It is a powerful tool for teachers to teach and students to verify.

\section{Conclusion}

The teaching management system to follow to learn, and teaching philosophy is from the "teaching" and "learning" the best combination of reasonable design, simple operation, with more powerful function of teaching guidance, teaching process and learning process, data processing, teaching test etc. The process of planning, organization, command, coordination, control, is a powerful tool for teachers' teaching and students' learning. As one of the dynamic learning platform of the provincial excellent course, the teaching system has been applied in the actual teaching, and has achieved good results. It has a strong operability, practicability and reference [11].

\section{Acknowledgement}

In this paper, the research was sponsored by the Nature Science Foundation of Henan Province (Project No. 201112400450401) and Youth Fund Project of Luoyang Institute of Science and Technology (Project No. 2010QZ16). 


\section{References}

[1] LV Jing, MIT. Enlightenment of open courses on the construction of top-quality courses in China [J]. China educational technology equipment, 2013, (27): 135-136.

[2] Wang Ying, Zhang Jinlei, Zhang Baohui. Characteristic analysis and Enlightenment of large-scale network open course (MOOC) typical project [J]. Journal of distance education, 2013, (4): 67-74.

[3] Wang Weiguo. Talking about object oriented method in software engineering [J]. forum for science and technology, 2015, (3): 76-77.

[4] Zhao Qin. Research and significance of the excellent course website [J]. new curriculum study, 2011, (5): 130.

[5] Tang Yaner, Liu Zhaoshan,.MITOCW project and national excellent course construction concept and comparison of operation mechanism [J]. modern distance education research, 2014, (3): 55-59.f81

[6] Xu Xu, Xu Enqin, Zhang Guijuan. Comparative analysis of domestic excellent courses and MITOCW network teaching resources [J]. China education information, 2015, (5): 6-11.

[7] Sang Xinmin, Li Shuhua, Xie Yangbin. Cultural strategy interpretation of Jobs's question: deep thinking on the new trend of online curriculum [J]. open education research, 2016, (3): 30-41.

[8] Wu Weining. Open courses on large scale networks (MOOC): Courser, comments on Tian. Heilongjiang education, 2014, (2): 39-41.

[9] Wang Aihua, Wang Qiong. Comparative study of the shared use of quality courses and open courses abroad [J]. China distance education, 2016, (6): 16-21.

[10] Liu Ning,.Coursera:. Characteristics and implications of new online education [J]. academy, 2017, (12): 68-71.

[11] Fahad, Alhumaidan., State, Based, and, Dynamic, Formal, Analysis, of, UML, State, Diagrams, [J]., Journal, of, Software, Engineering,, and, Applications, 2014,5 (Static): 483-491. 